OPEN ACCESS

Edited by:

Jun $Q u$,

Oak Ridge National Laboratory (DOE),

United States

Reviewed by:

Peter J. Blau,

Blau Tribology Consulting,

United States

*Correspondence:

Valentin L. Popov

v.popov@tu-berlin.de

Specialty section:

This article was submitted to

Tribology,

a section of the journal

Frontiers in Mechanical Engineering

Received: 31 May 2018 Accepted: 16 October 2018 Published: 19 November 2018

Citation:

Popov VL (2018) Is Tribology Approaching lts Golden Age? Grand Challenges in Engineering Education

and Tribological Research.

Front. Mech. Eng. 4:16.

doi: 10.3389/fmech.2018.00016

\section{Is Tribology Approaching Its Golden Age? Grand Challenges in Engineering Education and Tribological Research}

\author{
Valentin L. Popov* \\ Technische Universität Berlin, Berlin, Germany
}

In spite of its obvious importance, the subject of tribology has relatively low visibility in the engineering community and among the general public. The author's hypothesis is that this problem is at least partly due to the poor "availability" of tribology. In other words, there are practically no simple methods or concepts having high predictive power for tribological problem-solving. That situation is due to the extremely inter-disciplinary and multi- scale character of tribological processes. Fortunately, however, recent methodical and didactical developments in the field of tribology offer hope that the situation may soon change. It is time to integrate certain basic aspects of the mechanics of interfaces into the curricula of technical universities. The author further argues that one of the key problems confronting tribology and its future grand challenges is solving the problem of the "third body."

\section{Keywords: contact mechanics, lubrication, wear, adhesion, tribochemistry, elastohydrodynamics, boundary} element method, third body

\section{INVISIBLE TRIBOLOGY}

Whether a technical device or a living being-every system is made up of connected parts. These connections of various kinds-from simple supports to rivets, screws, glued connections, various types of bearings, wheels, and so on are the subject of a science named Tribology. Tribology is a subject integral to any mechanical system containing moving parts or joints-starting with molecular "machines" (as motor proteins in living cells) (Dudko et al., 2003) and micro and nano mechanical systems (Bhushan et al., 1995) over the huge field of traditional macroscopic tribology (Dowson, 1979) up to the contacts between tectonic plates (Scholz, 2002). The word "Tribology" was introduced 1966 by the British commission guided by Jost (1966). The Jost Report identified incorrect lubrication and the accompanying wear and friction issues as the main reasons for the failure of mechanical systems. Since then it is has been (somewhat) widely recognized that tribology has immediate influence on global energy consumption, costs and emissions-key technological and hot political issues of the modern society (Holmberg and Erdemir, 2017). And yet, if you ask people on the street what "Tribology" is, most of them will not be able to associate this word with any practical object or problem. How can the tremendous importance of tribology be reconciled with its relatively low social and technological visibility? 


\section{WHAT IS THE REASON FOR LOW VISIBILITY OF TRIBOLOGY?}

The answer may lie in the poor availability of tribology to the broader engineering community. Scientific and technological visibility and public perception of each discipline is determined not only by its importance but very decisively also by its availability. Thus, Analysis was almost a sacral science only for a few "initiates" until Leibnitz invented his intuitive and practical notations (Leibnitz, 1674-1676). This seemingly "merely didactical" invention made Analysis available literally for everybody-now it is a part of the curriculum of any high school. The availability of a subject is strongly associated with its complexity, and the complexity of the mechanics and physics of interfaces is notoriously high. Just a superficial glance in an anatomic atlas (Bourgery, 2017) shows that the main elements of the supporting structure of the human body, bones, arein spite of their complicated internal structure-much simpler than the joints. The latter have a truly spectacular architecture and very specialized material properties, which still cannot be reproduced artificially (Jin and Dowson, 2013). No wonder that it is much more difficult to repair the joints than it is to mend bones. Structural elements and their joints are both omnipresent in a variety of systems-they are both generic, unavoidable aspects of any structure. The difference between them is in the availability of models used to describe them: For the basics of mechanics of materials students only need proficiency in analysis of one variable and the simplest ordinary differential equations, while the simplest (Hertzian) contact problem is formulated as an integral equation with mixed boundary conditions. This qualitative difference in complexity is the reason for the fact that students of almost all engineering majors study the theory of beams in their first or second semester, but only acquire a very rudimentary notion of the mechanics of connections.

\section{DID TWO CENTURIES SINCE THE WORK OF COULOMB BRING PROGRESS?}

Tribology is the science of friction, wear and lubrication. The first experimental study of friction that was broadly publicly discussed and had a decisive impact on the subsequent development of science and engineering seems to be the memoir of Amontons (1699). He was the first to formulate, based on experimental observations, the "law of friction" which is now widely known as "Amontons' law." In 1781 Charles Augustin de Coulomb published his remarkable, timeless book on friction (see available later edition, Coulomb, 1821) where he described many properties of dry friction that even today remain subjects of active research. In particular, he investigated the dependency of the coefficient of friction on time, velocity, normal force, apparent contact area, humidity and material pairing. Some of his observations-e.g., the explicit time dependency of the coefficient of friction-have been understood only two hundred years later (Rice and Ruina, 1983; Dieterich and Kilgore, 1994) and many remain not understood to this day. For example, Coulomb found that the intensity of friction in the contact of wood on metal, depending on the duration of contact, slowly increases and reaches its peak after 4-5 days, and sometimes more. In contact of two metals, friction shows completely different behavior: it achieves the stationary value in an instant. In wood on wood contact friction achieves the stationary value in a few minutes (Popova and Popov, 2015). These observations are more than 200 years old, but only began to be understood on the micro scale very recently (Carpick and Bennewitz, 2014).

The most striking deficiency in the current state of the art of tribology, is that we still cannot predict the coefficient of friction in practically any pairing, and in many cases we even do not really understand what the main governing parameters are. This is due to the complexity of physical processes determining tribological properties (Persson and Tosatti, 1996): contact interactions, adsorbed layers (Robbins and Krim, 1998; He et al., 1999; Müser et al., 2001), tribochemical reactions, mixing processes and wear (Scherge et al., 2003), elastohydrodynamic lubrication (Ertel, 1939; Hamrock and Dowson, 1977), boundary lubrication (Kenausis et al., 2000), shear melting (Persson and Popov, 2000), cavitation (Etsion, 2013; Savio et al., 2016), adhesion (Rabinowicz, 1961), interaction with system dynamics (Kado et al., 2014; Teidelt, 2015; Milahin, 2016; Wetter, 2016) material properties (Khadem et al., 2017) and fracture mechanics (Ciavarella et al., 1999) - to mention only some.

Clearly, there are many complex tribology problems which have been solved, as e.g., those connected with hydrodynamic and elastohydrodynamic lubrication. It should also be noted that many tribological problems have been met with working practical solutions-otherwise we would not have functioning cars, trains, airplanes, and other modern conveniences. Nonetheless, many such solutions were arrived at mostly by trial and error, in combination with iterative improvement. Many fundamental problems, particularly those involving dry and boundary lubrication remain not well understood.

\section{IS THE TIME RIPE FOR A "REVOLUTION" IN TRIBOLOGY?}

Several developments of the last decades have the potential to change the future standing of tribology among other engineering sciences. Consider, for example, the theories of hydrodynamic and elastohydrodynamic lubrication (Hamrock and Dowson, 1981), understanding of hard coatings (Donnet and Erdemir, 2008) and lubrication additives (Spikes, 2004).

In the following I would like to discuss in more detail two key developments that concern contact mechanics.

\section{FFT-Based Boundary Element Method: Searching for Consensus and New Paradigms in Tribology}

The first of these developments is an extremely effective numerical simulation method of contact of rough surfaces. It is known as the Fast Fourier Transform-based Boundary Element Method, or FFT-BEM. Following years of debate on the underlying theory, the engineering community created a 
tool that allows direct calculation of realistic contact conditions. Several modifications of this method are mentioned in Müser et al. (2017). The most common version of the FFT-Based Boundary Element Method (Putignano et al., 2012) can be applied both to normal and tangential contacts with arbitrary contact interaction (Pohrt and Li, 2014), to viscoelastic bodies (Carbone and Putignano, 2013; Kusche, 2016) and adhesive (Popov et al., 2017; Rey et al., 2017) contacts. This method recently became the standard method of numerical simulation of tribological contacts both in academic and industrial research and development and changed significantly the ways of thinking and the direction of further development of tribology. While around 2010 high resolution simulations of contact of rough surfaces were available to only a few leading groups worldwide, now they can be carried out in practically every tribological group, the corresponding programs are even provided for on-line simulations (Tribology Simulator, 2018).

\section{Progress in Didactics of Contact Mechanics Since Hertz}

The second development is more of didactical nature. It does not contribute much to the results obtained in 136 years since the seminal work of Hertz (1882) but merely presents them in a form accessible even to undergraduate students. This didactic invention is the Method of Dimensionality Reduction (MDR) (Popov and Heß, 2015) which can be considered a reformulation of the solution method for contact of axi-symmetrical bodies first developed by Schubert (1942). In the literature, Schubert's method is mostly associated with the name of Sneddon, due to the Sneddon's highly cited paper (Sneddon, 1965). In reality, the method was suggested not only by Schubert but (later) also by Green and Zerna (1954), Collins (1959), and Galin (1961) but it took decades until it became well-known and "established" and Sneddon indeed did much for advertising this solution, including the translation and publication of the book of Galin.

The MDR, according to Barber (2018), is basically a reinterpretation of the equations of Schubert-Galin-Sneddon using a simple contact with a one-dimensional elastic foundation. MDR summarizes the known solutions and presents them in a simply reproducible mnemonic form. The true added value of the MDR becomes visible only when considering more general problems. Due to theorems allowing for (exact or approximate) reduction of tangential contact problems (Cattaneo, 1938; Mindlin, 1949; Jäger, 1995; Ciavarella, 1998), viscoelastic contact problems (Radok, 1957) and adhesive contact problems (Johnson et al., 1971) to non-adhesive normal contact, the MDR becomes a very compact, universal and intuitive tool for understanding and analyzing a great variety of contact problems. As a matter of fact, it provides a sort of "pocket edition" of all solutions in contact mechanics of point contacts obtained by researchers in the last 136 years. This didactic tool requires only the basics of analysis for its application and thus makes contact mechanics available to a broad engineering community. Barber notes that MDR is comparable with the moment-area method for the solution of beam deflection problems in the mechanics of materials. Both have restricted fields of applicability-but wide enough to be worth studying by engineers; both are simple and instructive. All major problems of the mechanics of connections-such as normal and tangential contact, stresses at the surface and inside the material, viscoelastic contacts, adhesion, wear and fretting, influence of shape, and material gradients (Heß, 2016) on adhesive strength and wear as well as damping in oscillating contacts-this complete spectrum of essential contact problems can be analyzed with MDR without using complicated mathematical tools. However, integrating contact mechanics in the basic engineering courses remains a great challenge.

\section{A GRAND CHALLENGE IN RESEARCH OF FRICTION: "THIRD BODY"}

Surfaces have essentially different properties compared with the bulk of materials, and tribological loading massively changes the properties of surface layers. The interface properties of tribological contacts may be influenced by the composition of the atmosphere, humidity, presence of lubricants, adsorbed layers, and wear debris. The intermediate space of and around the interface essentially determines the tribological properties and is called "third body" (Godet, 1990). To exaggerate somewhat, understanding friction means understanding the third body. The influence of the third body in a broad sense has been demonstrated on all scales. Thus, one of the great discoveries of nanotribology was structural superlubricity in the contact of well-prepared atomically smooth surfaces (Dienwiebel et al., 2004). However, the presence of flakes of lamellar solids that can freely rotate completely destroys the effect of superlubricity (Filippov et al., 2008). A similar effect can be due also to other impurities in the interface, even of single atoms (Müser et al., 2001). Under other conditions, interfacial processes are needed to achieve the state of low friction (Li et al., 2011). Intermixing and surface modification are also essential in classical macroscopic tribology, such as in combustion engines, where the formation of a chemically modified surface layer was shown to be the key for understanding tribological properties (Scherge et al., 2003). Even in systems with hard coatings, where, at the first glance, the essential role should be played by material properties, in reality it is the surface modification of these properties which does matter (Pastewka et al., 2010). The same is valid on the mesoscale: surface changes lead to time dependent kinetics of tribological properties (Ostermeyer, 2003). Contact mechanics of rough surfaces made enormous progress in recent years, but its necessary input, the surface topography, doesn't remain static in the course of a tribological process. Thus, one of the most valuable and effective modern tools of looking into the interface-the FFT-based BEM helps understanding the given configuration of the surfaces but does not help understanding its changes as it cannot describe inelastic behavior and is not capable of describing such highly non-linear processes as formation of wear debris and material intermixing. Finding new concepts for 
characterizing and understanding the third body is therefore an urgent need of tribology and one of its great challenges.

We hope that now is the right time to approach this "problem of the third body." On the empirical level it could be a combination of non-equilibrium thermodynamics of surface layers, similar to the framework used in Bryant et al. (2008) and kinetics of formation and wear of the surface layers similar to the works of Ostermeyer and Müller (2006). For example, it is generally recognized that in lubricated contacts the wear process is controlled by formation and wearing out of the boundary lubrication layer build trough mechanochemical reactions of additives with the surfaces. The wear process of this boundary layer could be described in the general framework suggested in 1958 by Rabinowicz (1995) and confirmed by direct quasimolecular simulations in Aghababaei et al. (2016). This concept is a generic and robust approach as it basically says that the wear particles can appear if the stored elastic energy is sufficient for their formation. The process of wear particle initiation has to be completed by mechanics of wear debris in the gap between two bodies and the transport of wear particles. The latter could be described using a macroscopic empirical framework similar to Schargott (2009). The reverse process of the layer deposition can be described using the classical concept of mechanically activated thermal processes (Spikes, 2018) which was validated experimentally also for the particular process of additive deposition (Gosvami et al., 2015). Detailed discussion of the current state of tribology and its topical problems can be found in a collaborative analysis (Vakis et al., 2018). The above suggestions are of course only my personal attempt to predict the future development of understanding of the third body.

\section{REFERENCES}

Aghababaei, R., Warner, D. H., and Molinari, J.-F. (2016). Critical length scale controls adhesive wear mechanisms. Nat. Commun. 7:11816. doi: $10.1038 /$ ncomms11816

Amontons, G. (1699). De la resistance cause'e dans les machines (About resistance and force in machines). Mem l'Acedemie R: 257-282.

Barber, J. R. (2018). Contact Mechanics. Solid Mechanics and Its Applications. Springer.

Bhushan, B. (Ed.) (2017). Nanotribology and Nanomechanics. Heidelberg: Springer International.

Bhushan, B., Israelachvili, J. N., and Landman, U. (1995). Nanotribology: friction, wear and lubrication at the atomic scale. Nature 374, 607-616. doi: $10.1038 / 374607 \mathrm{a} 0$

Bourgery, J. M. (2017). Jean Marc Bourgery. Atlas of Human Anatomy and Surgery, 12th Edition. Cologne: Taschen.

Bryant, M., Khonsari, M., and Ling, F. (2008). On the thermodynamics of degradation. Proc. R. Soc. 464, 2001-2014. doi: 10.1098/rspa.2007.0371

Carbone, G., and Putignano, C. (2013). A novel methodology to predict sliding and rolling friction of viscoelastic materials: theory and experiments. J. Mech. Phys. Solids 61, 1822-1834. doi: 10.1016/j.jmps.2013.03.005

Carpick, R. W., and Bennewitz, R. (2014). Let it slip. Nat. Phys. 10, 410-411. doi: $10.1038 /$ nphys 2985

Cattaneo, C. (1938). Sul Contatto di Due Corpi Elastici: Distribuzione Locale Degli Sforzi. Rendiconti dell'Accademia nazionale dei Lincei. 27, 342-348, 434-436, 474-478.

Ciavarella, M. (1998). The generalized Cattaneo partial slip plane contact problem. I-Theory. Int. J. Solids Struct. 35, 2349-2362. doi: 10.1016/s0020-7683(97)00154-6

\section{GOLDEN AGE OF TRIBOLOGY}

Classical tribology covering such applications as ball bearings, gear drives, clutches, brakes, etc. was developed in the context of mechanical engineering. But now contact mechanics and tribology expand to qualitatively new fields of applications, which are at the forefront of the global development trends of technology and society, in particular micro- and nanotechnology (Bhushan, 2017) as well as biology (Gorb, 2009) and medicine (Willert et al., 2005; Paterson, 2007; Li et al., 2008). At the same time, tribology developed experimental methods, theoretical concepts, and numerical tools allowing effectively mastering the seemingly complicated physics and mechanics of interconnections. After intensive and controversial discussions, recently, several attempts have been undertaken to achieve consensus on the present state and available tools of tribology (Müser et al., 2017; Vakis et al., 2018). These attempts and the rapid expansion into new research areas such as nano-technology and life sciences give hope that the coming years will be a true golden age of tribology.

\section{AUTHOR CONTRIBUTIONS}

The author confirms being the sole contributor of this work and has approved it for publication.

\section{ACKNOWLEDGMENTS}

I am deeply grateful to the reviewer, Peter J. Blau, for constructive criticism and many valuable suggestions.

Ciavarella, M., Demelio, G., and Hills, D. A. (1999). “The use of almost complete contacts for fretting fatigue tests," in Fatigue and Fracture Mechanics: 29th Volume. eds T. L. Panontin and S. D. Sheppard (West Conshohocken, PA: American Society for Testing and Materials), 696-709.

Collins, W. D. (1959). On the solution of some axisymmetric boundary value problems by means of integral equations, II: further problems for a circular disc and a spherical cap. Mathematika 6:120. doi: 10.1112/s0025579300002023

Coulomb, C. A. (1821). Theorie des Machines Simple (Theory of Simple Machines). Paris: Bachelier.

Dienwiebel, M., Verhoeven, G. S., Pradeep, N., Frenken, J. W. M., Heimberg, J. A., and Zandbergen, H. W. (2004). Superlubricity of Graphite. Phys. Rev. Lett. 92:126101. doi: 10.1103/physrevlett.92.126101

Dieterich, J. H., and Kilgore, B. D. (1994). Direct observation of frictional contacts: new insights for state-dependent properties. Pure Appl. Geophys. 143, 283-302. doi: $10.1007 /$ bf00874332

Donnet, C., and Erdemir, A. (Eds.) (2008). Tribology of Diamond-Like Carbon Films. New York, NY: Springer.

Dowson, D. (1979). History of Tribology. New York, NY: Longman Limited.

Dudko, O. K., Filippov, A. E., Klafter, J., and Urbakh, M. (2003). Beyond the conventional description of dynamic force spectroscopy of adhesion bonds. Proc. Natl. Acad. Sci. U.S.A. 100, 11378-11381. doi: 10.1073/pnas.15345 54100

Ertel, A. M. (1939). Hydrodynamic lubrication based on new principles. Akad. Nauk. SSSR, Prikladnaya Matematika i Mekhanika 3, 41-52

Etsion, I. (2013). Modeling of surface texturing in hydrodynamic lubrication. Friction 1, 195-209. doi: 10.1007/s40544-013-0018-y

Filippov, A. E., Dienwiebel, M., Frenken, J. W. M., Klafter, J., and Urbakh, M. (2008). Torque and Twist against Superlubricity. Phys. Rev. Lett. 100:046102. doi: 10.1103/physrevlett.100.046102 
Galin, L. A. (1961). Contact Problems in the Theory of Elasticity. Raleigh, NC: North Carolina State College.

Godet, M. (1990). Third-bodies in tribology. Wear 136, 29-45. doi: 10.1016/0043-1648(90)90070-q

Gorb, S. N. (Ed.) (2009). Functional Surfaces in Biology. Springer.

Gosvami, N. N., Bares, J. A., Mangolini, F., Konicek, A. R., Yablon, D. G., and Carpick, R. W. (2015). Mechanisms of antiwear tribofilm growth revealed in situ by single-asperity sliding contacts. Science 348, 102-106. doi: $10.1126 /$ science. 1258788

Green, A. E., and Zerna, W. (1954). Theoretical Elasticity. Oxford: Clarendon Press.

Hamrock, B. J., and Dowson, D. (1977). Isothermal elastohydrodynamic lubrication of point contacts: part iii-fully flooded results. J. Lubric. Tech. 99, 264. doi: $10.1115 / 1.3453074$

Hamrock, B. J., and Dowson, D. (1981). Ball Bearing Lubrication. New York, NY: Wiley \& Sons.

He, G., Müser, M. H., and Robbins, M. O. (1999). Adsorbed layers and the origin of static friction. Science 284, 1650-1652.

Hertz, H. (1882). Über die Berührung fester elastischer Körper. Journal für die reine und angewandte Mathematik 92, 156-171. doi: 10.1515/crll.1882.92.156

Heß, M. (2016). A simple method for solving adhesive and non-adhesive axisymmetric contact problems of elastically graded materials. Int. J. Eng. Sci. 104, 20-33. doi: 10.1016/j.ijengsci.2016.04.009

Holmberg, K., and Erdemir, A. (2017). Influence of tribology on global energy consumption, costs and emissions. Friction 5, 263-284. doi: 10.1007/s40544-017-0183-5

Jäger, J. (1995). Axi-symmetric bodies of equal material in contact under torsion or shift. Arch. Appl. Mech. 65, 478-487. doi: 10.1007/s004190050033

Jin, Z., and Dowson, D. (2013). Bio-friction. Friction 1, 100-113. doi: 10.1007/s40544-013-0004-4

Johnson, K. L., Kendall, K., and Roberts, A. D. (1971). Surface energy and the contact of elastic solids. Proc. R. Soc. 324, 301-313. doi: 10.1098/rspa.1971. 0141

Jost, H. P. (Ed.) (1966). Lubrication (Tribology) - A Report on the Present Position and Industry's Needs. Department of Education and Science, HM. Stationary Office, London.

Kado, N., Tadokoro, C., and Nakano, K. (2014). Kinetic friction coefficient measured in tribotesting: influence of frictional vibration. Tribology Online 9, 63-70. doi: 10.2474/trol.9.63

Kenausis, G. L., Vörös, J., Elbert, D. L., Huang, N., Hofer, R., Ruiz-Taylor, L., et al. (2000). Poly(l-lysine)-g-Poly(ethylene glycol) layers on metal oxide surfaces: attachment mechanism and effects of polymer architecture on resistance to protein adsorption. J. Phys. Chem. B 104, 3298-3309. doi: 10.1021/jp99 $3359 \mathrm{~m}$

Khadem, M., Penkov, O. V., Yang, H.-K., and Kim, D.-E. (2017). Tribology of multilayer coatings for wear reduction: a review. Friction 5, 248-262. doi: 10.1007/s40544-017$0181-7$

Kusche, S. (2016). Frictional force between a rotationally symmetric indenter and a viscoelastic half-space. ZAMM 97, 226-239. doi: 10.1002/zamm.2015 00169

Leibnitz, G. W. (1674-1676). Infinitesimalmathematik, Internetausgabe: Available online at: http://www.gwlb.de/Leibniz/Leibnizarchiv/Veroeffentlichungen/ VII5A.pdf; http://www.gwlb.de/Leibniz/Leibnizarchiv/Veroeffentlichungen/ VII5B.pdf

Li, J., Zhang, C., and Luo, J. (2011). Superlubricity behavior with phosphoric acid-water network induced by rubbing. Langmuir 27, 9413-9417. doi: $10.1021 / \operatorname{la} 201535 \mathrm{x}$

Li, Q. S., Lee, G. Y. H., Ong, C. N., and Lim, C. T. (2008). AFM indentation study of breast cancer cells. Biochem. Biophys. Res. Commun. 374, 609-613. doi: $10.1016 /$ j.bbrc.2008.07.078

Milahin, N. (2016). Robuste Einflussparameter für Reibung und Oberflächenmodifizierung unter Einfluss von Ultraschall. Ph.D. thesis. Technische Universität Berlin.

Mindlin, R. D. (1949). Compliance of elastic bodies in contact. J. Appl. Mech. 16, $259-268$.

Müser, M. H., Dapp, W. B., Bugnicourt, R., Sainsot, P., Lesaffre, N., Lubrecht, T. A., et al. (2017). Meeting the contact-mechanics challenge. Tribol. Lett. 65:4. doi: $10.1007 /$ s11249-017-0900-2
Müser, M. H., Wenning, L., and Robbins, M. O. (2001). Simple microscopic theory of amontons's laws for static friction. Phys. Rev. Lett. 86, 1295-1298. doi: 10.1103/PhysRevLett.86.1295

Ostermeyer, G. (2003). On the dynamics of the friction coefficient. Wear 254 852-858. doi: 10.1016/s0043-1648(03)00235-7

Ostermeyer, G. P., and Müller, M. (2006). Dynamic interaction of friction and surface topography in brake systems. Tribology Int. 39, 370-380. doi: 10.1016/j.triboint.2005.04.018

Pastewka, L., Moser, S., Gumbsch, P., and Moseler, M. (2010). Anisotropic mechanical amorphization drives wear in diamond. Nat. Mater. 10, 34-38. doi: $10.1038 /$ nmat2902

Paterson, M. (2007). The Senses of Touch : Haptics, Affects and Technologies. Oxford: Berg.

Persson, B. N. J., and Popov, V. L. (2000). On the origin of the transition from slip to stick. Solid State Commun. 114, 261-266. doi: 10.1016/s0038-1098(00)00045-4

Persson, B. N. J., and Tosatti, E. (Eds.) (1996). Physics of Sliding Friction. Heidelberg: Springer.

Pohrt, R., and Li, Q. (2014). Complete boundary element formulation for normal and tangential contact problems. Phys. Mesomechan. 17, 334-340. doi: 10.1134/s1029959914040109

Popov, V. L., and Heß, M. (2015). Method of Dimensionality Reduction in Contact Mechanics and Friction. Berlin: Springer.

Popov, V. L., Pohrt, R., and Li, Q. (2017). Strength of adhesive contacts: influence of contact geometry and material gradients. Friction 5, 308-325. doi: 10.1007/s40544-017-0177-3

Popova, E., and Popov, V. L. (2015). The research works of Coulomb and Amontons and generalized laws of friction. Friction 3, 183-190. doi: 10.1007/s40544-015-0074-6

Putignano, C., Afferrante, L., Carbone, G., and Demelio, G. (2012). A new efficient numerical method for contact mechanics of rough surfaces. Int. J. Solids Struct. 49, 338-343. doi: 10.1016/j.ijsolstr.2011.10.009

Rabinowicz, E. (1961). Influence of surface energy on friction and wear phenomena. J. Appl. Phys. 32, 1440-1444. doi: 10.1063/1.1728375

Rabinowicz, E. (1995). Friction and Wear of Materials. Second Edition. New York, NY: John Wiley \& Sons, Inc.

Radok, J. R. M. (1957). Viscoelastic stress analysis, Quart. Appl. Math 15, 198-202.

Rey, V., Anciaux, G., and Molinari, J.-F. (2017). Normal adhesive contact on rough surfaces: efficient algorithm for FFT-based BEM, resolution. Comput Mech. 60, 69-81. doi: 10.1007/s00466-017-1392-5

Rice, J. R., and Ruina, A. L. (1983). Stability of steady frictional slipping. J. Appl. Mech. 50:343. doi: 10.1115/1.3167042

Robbins, M. O., and Krim, J. (1998). Energy dissipation in interfacial friction. MRS Bull. 23, 23-26. doi: 10.1557/s088376940 003058x

Savio, D., Pastewka, L., and Gumbsch, P. (2016). Boundary lubrication of heterogeneous surfaces and the onset of cavitation in frictional contacts. Sci. Adv. 2:e1501585. doi: 10.1126/sciadv.1501585

Schargott, M. (2009). A multi-scale approach for dynamical simulations of the surface topography in high-pressure frictional contacts: bridging simulation scales. Tribol. Lett. 39, 9-17. doi: 10.1007/s11249-009-9500-0

Scherge, M., Shakhvorostov, D., and Pöhlmann, K. (2003). Fundamental wear mechanism of metals. Wear 255, 395-400. doi: 10.1016/s0043-1648(03)00273-4

Scholz, C. H. (2002). The Mechanics of Eathquakes and Faulting, Second Edition. Cambridge: Cambridge University Press.

Schubert, G. (1942). Zur Frage der Druckverteilung unter elastisch gelagerten Tragwerken. Ingenieur-Archiv. 13, 132-147. doi: 10.1007/bf02095912

Sneddon, I. N. (1965). The relation between load and penetration in the axisymmetric boussinesq problem for a punch of arbitrary profile. Int. J. Eng. Sci. 3, 47-57. doi: 10.1016/0020-7225(65)90019-4

Spikes, H. (2004). The history and mechanisms of ZDDP. Tribol. Lett. 17, 469-489. doi: 10.1023/b:tril.0000044495.26882.b5

Spikes, H. (2018). Stress-augmented thermal activation: tribology feels the force. Friction 6, 1-31. doi: 10.1007/s40544-018-0201-2

Teidelt, E. (2015). Oscillating Contacts: Friction Induced Motion and Control of Friction. PhD thesis, Technische Universität Berlin.

Tribology Simulator (2018). Available online at: http://www.tribonet.org/ cmdownloads/tribology-simulator/ 
Vakis, A. I., Yastrebov, V. A., Scheibert, J., Nicola, L., Dini, D., Minfray, C., et al. (2018). Modeling and simulation in tribology across scales: an overview. Tribol. Int. 125, 169-199. doi: 10.1016/j.triboint.2018. 02.005

Wetter, R. (2016). The Interplay of System Dynamics and Dry Friction: Shakedown, Ratcheting and Micro-Walking. Ph.D. thesis, Technische Universität Berlin.

Willert, H.-G., Buchhorn, G. H., Fayyazi, A., Flury, R., Windler, M., Köster, G., et al. (2005). Metal-on-metal bearings and hypersensitivity in patients with artificial hip joints. J. Bone Joint Surg. 87, 28-36. doi: 10.2106/ jbjs.a.02039pp
Conflict of Interest Statement: The author declares that the research was conducted in the absence of any commercial or financial relationships that could be construed as a potential conflict of interest.

Copyright (๑) 2018 Popov. This is an open-access article distributed under the terms of the Creative Commons Attribution License (CC BY). The use, distribution or reproduction in other forums is permitted, provided the original author(s) and the copyright owner(s) are credited and that the original publication in this journal is cited, in accordance with accepted academic practice. No use, distribution or reproduction is permitted which does not comply with these terms. 